\title{
Prevalence of Overweight and Obesity among School-Going Children of Aligarh City and Its Association with Socio-Demographic Variables
}

\author{
Aijaz Fatima, Anisa M. Durrani
}

\begin{abstract}
In India, the prevalence of overweight and obesity in urban areas is comparable with some developing countries. A rapid transition in food practices, lifestyle factors, behavioural factors, physical inactivity and adopting western culture are some of the causes responsible for this problem. Children from small towns are experiencing nutritional changes due to their tendency to try eating pattern of larger cities. Aims and objectives: To study the prevalence of overweight and obesity and related risk factors among school going children of Aligarh city.Materials and methods: A cross - sectional study was done among four schools from four zones of Aligarh city. A total of 900 children studying in classes Ist to Vth were taken in the study. A predesigned and pretested questionnaire was used to collect data on sociodemographic, dietary intake, lifestyle, behavioural factors, physical activity and anthropometric measurements. Results: Overall Prevalence of overweight and obesity was $8.1 \%$ and $8.2 \%$ among school-going children. There was a statistically significant difference in prevalence of overweight and obesity among affluent schools (6.1\% and 6.7\%) and nonaffluent schools (2.0\% and $1.6 \%)$ respectively was observed. The related risk factors for overweight and obesity were affluence and higher level of father's education etc. Conclusion: Overweight and obesity among school-going children is a major problem facing even in smaller cities in India.Interventions must be taken to focus on communicating and educating teachers and parents, especially of the affluent section, towards restricting fast food intake, TV viewing and emphasizing the importance of physical activity.

Keyword: Prevalence, overweight, obesity, fast foods, health risks.
\end{abstract}

\section{INTRODUCTION} is childhood obesity.This is a global problem affecting many developed and developing countries both and especially in urban settings. Childhood overweight and obesity has become a risk factor for morbidity and mortality in later life.[1]. A dramatic increase in obesity widespread among children in recent years raised the number of obese children to be 41 million in 2016 according to WHO,

Revised Manuscript Received on February 08, 2020.

* Correspondence Author

Aijaz Fatima*, Research scholar, Department of Home Science, Faculty of Agricultural Sciences, Aligarh Muslim University, Aligarh, Uttar Pradesh, India. Email: aijaztayyab1972@gmail.com

Prof. Anisa M. Durrani, Department of Home Science, Faculty of Agricultural Sciences, Aligarh Muslim University, Aligarh, Uttar Pradesh, India.

(C) The Authors. Published by Blue Eyes Intelligence Engineering and Sciences Publication (BEIESP). This is an open access article under the CC BY-NC-ND license (http://creativecommons.org/licenses/by-nc-nd/4.0/)
One of the most serious health problems of 21st century

2018[2]. Chronic illnesses like dyslipidaemia, type II diabetes and hypertension are developing at a fast rate among children due to the scourge of obesity [3]. Children experience bullying, social stigmatization and social isolation as a result of obesity [4]. In India, a few studies on overweight and obesity among children have been done particularly in metropolitan cities. Present study was carried out keeping in mind the essential requirement of addressing the magnitude of problem of overweight and obesity among school children of Aligarh city.

There are certain risk factors partly responsible for overweight and obesity among school -going children including sociodemographic groups, dietary intake, lifestyle, behavioural factors and decreased levels of physical activity [5].

A description of obesity as one of today's most abandoned public health issue is given by The World Health Organization [6].

Is the nutritional transition affecting the young population in small towns of India imitating the larger cities? Is the modernization forcing children to adapt the behaviours and lifestyle of others? These research questions were kept in mind to conduct the present study among school-going children of Aligarh city. The following were the aims and objectives of the study:

1) To study the prevalence of overweight and obesity among school going children in Aligarh city and

2) To study its association with socio-demographic profile of the same.

\section{METHODOLOGY}

The present cross-sectional study was planned to investigate the prevalence of overweight and obesity and related risk factors among school going children in Aligarh city. The study was carried out during academic year 20172018. A total of 900 children from schools of Aligarh city between the age group of 7-12 years studying in classes Ist to Vth were taken to participate in the study. Aligarh city was divided in four zones to cover all parts of Aligarh city. Further, schools were selected from each zone randomly from the list obtained from the (Basic Shiksha Adhikari office Aligarh, 2018). Total four schools were selected for the study. Distribution of questionnaireswas done after the prior consent from the school authorities and parents. Parents were advised to fill the questionnaire themselves as the children were small. The sample size was determined using the formulaN=p91-p)/L^2 [7].

\section{Published By:}


A predesigned and pretested questionnaire was used to collect data on socio-demographic, dietary intake, lifestyle, behavioural factors, physical activity level and anthropometric measurements. Parents were informed to give detailsregarding their educational and occupational level, family history of obesity, hypertension and diabetes. Three-day dietary recall method was used to collect information on assessment of dietary intakes per day. As per total calorie requirement the dietary intakes of children as per age and sex were calculated as adequate- calorie intake, calorie-deficit or calorie -excess as recommended by the ICMR 2010. To assess the frequency of consumption of junk (unhealthy) foods and fruit intake during the last one month, a pretested food frequency questionnaire was used. These foods include samosas, bread pakoras, pakoras, patties, burgers, chowmein, cakes, pastries, namkeen, fries or chips etc. Children were asked about time spent in watching television, time spent in electronic gadgets, involvement in physical activity at home and at school every day during last one month. Total physical activity level was assessed by standard physical activity questionnaire. Standard equipment was used to take anthropometric measurements of weight and height. Measuring scale, bathroom scale, weighing machine and stadiometer were used to calculate Body Mass Index (BMI) of children[7].

BMI for age and sex percentiles was assessed to define Nutritional status of children according to WHO Growth reference, 2007[8]. All the children were categorized into 1) overweight 2) obese and non-overweight and non-obese. IBM SPSS version 23 was used to analyse the data and $\mathrm{p}<0.05$ was considered for statistical significance.

\section{ETHICAL CONSIDERATIONS}

The ethical clearance was obtained from the Institutional Bioethical Committee, Faculty of Agricultural Sciences, Aligarh Muslim University, Aligarh, U.P. (D.No.- 569/Ag). Prior permission was taken from the Supervisor and Chairperson of the Department of Home Science, Faculty of Agricultural Sciences, A.M.U. to conduct the survey and the same was initiated to the school authorities and parents of the school children.

\section{RESULTS}

Among the total study subjects $54.0 \%$ (486 out of 900) were males $46.0 \%$ (414 out of 900 ) were females. The age group of 7-9 years included $68.7 \%$ of school going children and $31.3 \%$ were in the $>10-12$ years age group. The nutritional status of the study population according to BMI has been shown in table 1 .

Table 1: Prevalence of overweight and obesity among school going children

\begin{tabular}{|c|c|c|}
\hline $\begin{array}{c}\text { Nutritional status according } \\
\text { to BMI }\end{array}$ & $\begin{array}{c}\text { Prevalence } \\
\mathrm{n}\end{array}$ & $\begin{array}{c}\text { Percentage } \\
(\%)\end{array}$ \\
\hline Underweight & 116 & $12.9 \%$ \\
\hline Normal & 637 & $70.8 \%$ \\
\hline Overweight & 73 & $8.1 \%$ \\
\hline Obese & 74 & $8.2 \%$ \\
\hline Total & 900 & $100 \%$ \\
\hline
\end{tabular}

Overall prevalence of overweight and obesity among school-going children was found to be $8.1 \%$ and $8.2 \%$, respectively table 1 . In spite of the fact a higher prevalence of overweight and obesity was found among boys (12.9\% overweight and obesity) as compared to girls (3.4\% overweight and obesity), the difference was statistically significant table 2 . The overall prevalence of overweight and

Table 2: Nutritional Status of the study subjects with respect to sex.

\begin{tabular}{|c|c|c|c|}
\hline $\begin{array}{c}\text { Nutritional } \\
\text { status } \\
\begin{array}{c}\text { According to } \\
\text { BMI }\end{array}\end{array}$ & $\begin{array}{c}\text { Male } \\
(\mathrm{n}=536) \\
(\%)\end{array}$ & $\begin{array}{c}\text { Female } \\
(\mathrm{n}=364) \\
(\%)\end{array}$ & $\begin{array}{c}\text { Total, } \mathrm{n} \\
(\%) \\
\mathrm{N}=900\end{array}$ \\
\hline Underweight & $63(7.0 \%)$ & $53(5.9 \%)$ & $\begin{array}{c}116 \\
(12.9 \%)\end{array}$ \\
\hline Normal & $\begin{array}{c}307 \\
(31.1 \%)\end{array}$ & $\begin{array}{c}330 \\
(36.7 \%)\end{array}$ & $\begin{array}{c}637 \\
(70.8 \%)\end{array}$ \\
\hline Overweight & $59(6.6 \%)$ & $14(1.6 \%)$ & $73(8.1 \%)$ \\
\hline Obese & $57(6.3 \%)$ & $17(1.9 \%)$ & $74(8.2 \%)$ \\
\hline
\end{tabular}

$\chi 2=45.586 ; \mathrm{df}=3 ; \mathrm{P}<0.05$

The risk of overweight and obesity was found to be significantly higher among school-children in the age group of 7 -9years $(12.0 \%)$ than in school- children in the age group of 10 -12years (4.3\%). The religion was found to have significant difference of (9.1\%) higher among Hindu school children than (7.2\%) among Muslim school- children. There was no statistically significant difference seen in regards to type of family and number of family members i.e. size of family. The prevalence rate of overweight and obesity was found higher in regard to ordinal position of school-children th (8.0\%) among 1-2nd born, (6.1\%) 3-4th born and (2.2\%) 4-5th born. Number of siblings found to have statistically significant difference with a prevalence of overweight of obesity (7.8\%) among children having two or more siblings, (6.7\%) among one sibling and (1.9\%) among only child with a statistically significant difference. otably, overweight and obese school-children had highe paternal education. The $37.6 \%$ school-children who were found to be overweight and obese had fathers with professional occupation,cation more than or equal to graduate. As can be seen in table 3 .

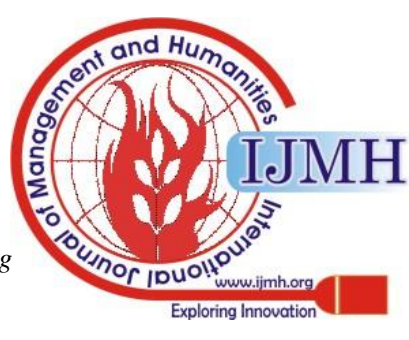


Table 3: Association of Nutritional status with Sociodemographic profile of Study subjects

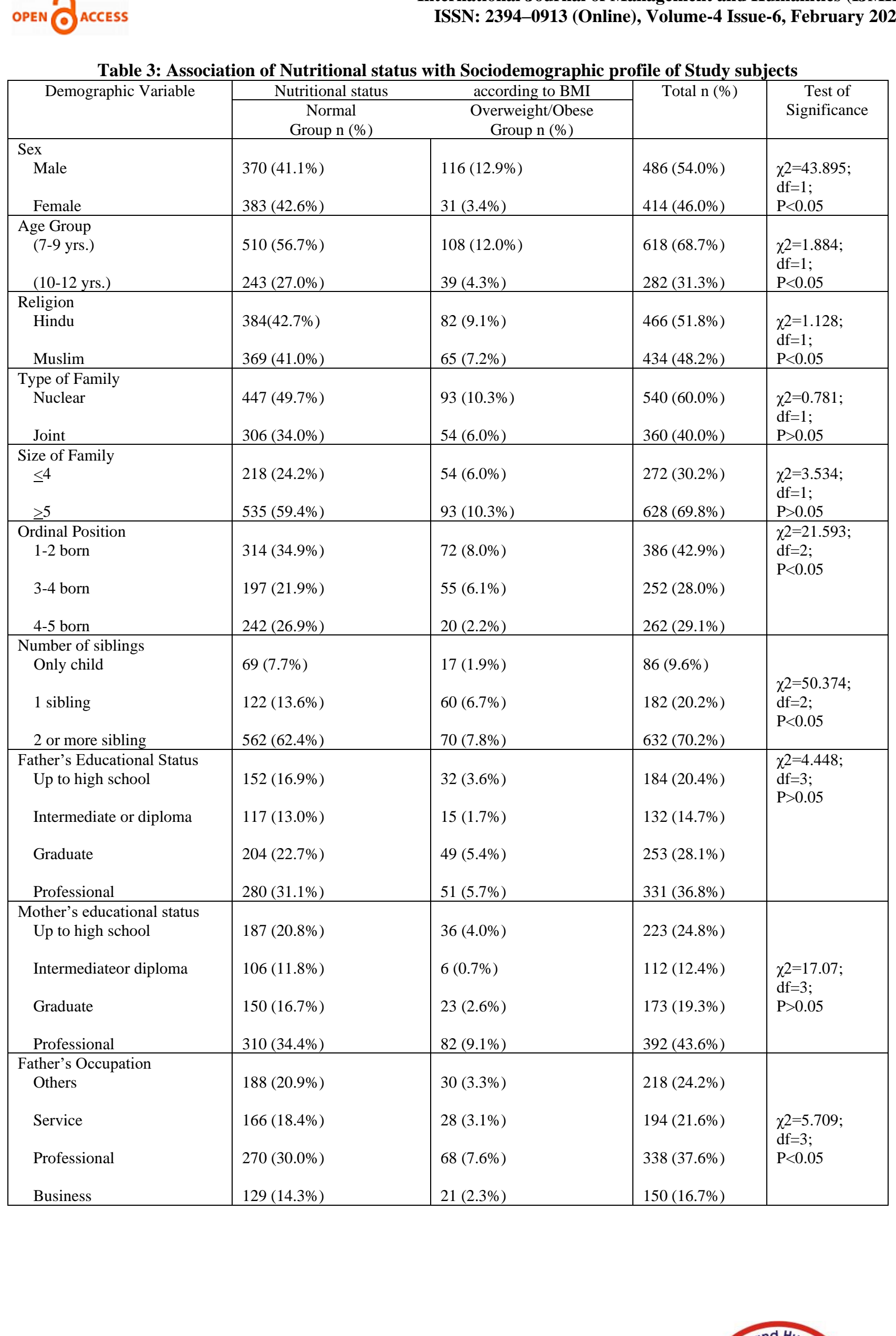


Prevalence of Overweight and Obesity among School-Going Children of Aligarh City and Its Association with SocioDemographic Variables

\begin{tabular}{|c|c|c|c|c|}
\hline $\begin{array}{l}\text { Mother's Occupation } \\
\text { Housework } \\
\text { Working }\end{array}$ & $\begin{array}{l}669(74.3 \%) \\
84(9.3 \%) \\
\end{array}$ & $\begin{array}{l}72(8.0 \%) \\
75(8.3 \%) \\
\end{array}$ & $\begin{array}{l}741(82.3 \%) \\
159(17.7 \%) \\
\end{array}$ & $\begin{array}{l}\chi 2=1.344 \\
\mathrm{df}=1 \\
\mathrm{P}<0.05\end{array}$ \\
\hline $\begin{array}{l}\text { Type of school } \\
\text { Affluent school } \\
\text { Non - affluent school }\end{array}$ & $\begin{array}{l}377(41.9) \\
376(41.8) \\
\end{array}$ & $\begin{array}{l}115(12.8 \%) \\
32(3.6 \%) \\
\end{array}$ & $\begin{array}{l}492(54.7 \%) \\
408(45.3 \%) \\
\end{array}$ & $\begin{array}{l}\chi 2=39.368 \\
\mathrm{df}=1 ; \\
\mathrm{P}<0.05\end{array}$ \\
\hline $\begin{array}{l}\text { Socio -economic status } \\
\text { Upper class }\end{array}$ & 249 (27.1\%) & 42 (4.7\%) & 291 (32.4\%) & \\
\hline $\begin{array}{l}\text { Upper middle class } \\
\text { Lower middle class }\end{array}$ & $\begin{array}{l}334(37.2 \%) \\
123(13.7 \%)\end{array}$ & $\begin{array}{l}77(8.6 \%) \\
22(2.4 \%)\end{array}$ & $\begin{array}{l}411(45.7 \%) \\
145(16.1 \%)\end{array}$ & $\begin{array}{l}\chi 2=3.518 \\
\mathrm{df}=3 \\
\mathrm{P}>0.05\end{array}$ \\
\hline $\begin{array}{l}\text { Upper lower and lower } \\
\text { class }\end{array}$ & 46 (5.1\%) & $6(0.7 \%)$ & 49 (5.8\%) & \\
\hline
\end{tabular}

In the non-affluent schools, the proportion of, underweight school children were significantly higher than in affluent schools. The proportion of school- children having normal weight was much higher in affluent schools (329 out of 900) 36.6\%. In addition, in the affluent schools, the proportion of overweight (6.1\%) and obese $(6.7 \%)$ school- children were significantly higher compared to nonaffluent schools. Looking at theends of the two extreme points, proportion of over-nutrition in affluent schools (12.8\% overweight andobesity) was much higher than under-nutrition (5.3\%) as can be seen in table 4 . Sociodemographic profile of the study population was studiedaccording to nutritional status, by applying Chi-square, and found to differ significantly between the affluent and non-affluent group. The nutritional status was found to differ significantly $(\chi 2=44.032, \mathrm{df}=3, \mathrm{P}<0.05)$ between the affluent and non-affluent group as shown in table 4.

Table 4: Nutritional Status of the study subjects with respect to type of school

\begin{tabular}{|c|c|c|c|}
\hline $\begin{array}{c}\text { Nutritional } \\
\text { status } \\
\text { According to } \\
\text { BMI }\end{array}$ & $\begin{array}{c}\text { Affluent } \\
\text { school }\end{array}$ & $\begin{array}{c}\text { Non- } \\
\text { affluent } \\
\text { school }\end{array}$ & $\begin{array}{c}\text { Total, } n \\
(\%) \\
\mathrm{N}=900\end{array}$ \\
\hline Underweight & $48(5.3 \%)$ & $\begin{array}{c}68 \\
(34.2 \%)\end{array}$ & $\begin{array}{c}116 \\
(12.8 \%)\end{array}$ \\
\hline Normal & $\begin{array}{c}329 \\
(36.6 \%)\end{array}$ & $\begin{array}{c}308 \\
(7.6 \%)\end{array}$ & $\begin{array}{c}637 \\
(70.7 \%)\end{array}$ \\
\hline Overweight & $55(6.1 \%)$ & $18(2.0 \%)$ & $73(8.1 \%)$ \\
\hline Obese & $60(6.7 \%)$ & $14(1.6 \%)$ & $74(8.2 \%)$ \\
\hline $2=44.032 ; \mathrm{df}=3 ; \mathrm{P}>0.05$ & &
\end{tabular}

\section{DISCUSSION AND CONCLUSION}

In Aligarh city, the prevalence of overweight and obesity among school-going children was found to be almost as high as in other big cities of our country [9]. In India childhood obesity has become a public health issue with (prevalence $>$ 5\%) [10]. In present study, we have introduced the extent of the prevalence of overweight and obesity among schoolgoing children between the age group pf 7-12 years in Aligarh city, by making use of individual weight and height measures to calculate the BMI. The overall prevalence of overweight and obesity was found $16.3 \%$ among schoolgoing children. The prevalence was found to be higher $(12.0 \%)$ in the age group of 7-9 years among school-going children.Asian countries are still facing a double burden of the problem of nutritional disease as a result of ongoing nutrition transition [11].The present study is evident of the double burden of malnutrition with a prevalence of being $12.8 \%$ (116 out of 900 ) underweight and $16.3 \%$ overweight (including obesity) among school - going children.Although, over-nutrition in affluent schools was found to be higher than undernutrition. The results of the study which was carried out on 500 students at Chhattisgarh among the children of 13-17 years showed that the prevalence of overweight (23.8\%) and obesity(8.4\%) which is higher and alarming for children. Another cross -sectional study done on 18,955 children in the age group of 6-11 years and adolescents 12-17 years, estimated a prevalence rate of $26.4 \%$ and $4.6 \%$ in private and government schools respectively in Chennai [12].An obesogenic environment has created by rapid urbanization resulting in motorized transport, dangerous roads and traffic, food courts, and by providing children with opportunities of entertainment and involving them in more sedentary activities. In India, specially the affluent segment of society has a rising trend of obesity. Even the small cities developing at a faster rate like Aligarh, are also spotting the problem of overweight and obesity among school -going children. A study conducted on 2,940 school - children in the age group of 6-12 years in Union Territory of Puducherry, the prevalence of overweight $4.98 \%$ and $2.24 \%$ of obesity [13].

Our study showed a higher prevalence (12.9\%) of overweight and obesity among males as compared to (3.4\%) in females. A similar study conducted Bhubaneshwar city on 537 children from the age group of 9-15 years showed a prevalence of $67.4 \%$ among boys and $32.6 \%$ among girls [14].Another study carried out on 3,851 children ranging in the age group of 3-17 years in Bangalore showed the prevalence rate of overweight and obesity among males $54.4 \%$ and $65.8 \%$ and females $45.6 \%$ and $34.2 \%$ respectively [15].

Published By:

Blue Eyes Intelligence Engineering

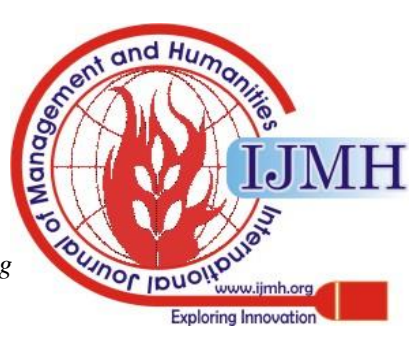


Present study revealed that school children of affluent school were more at risk of having overweight and obesity. This increasing trend of overweight and obesity has been shown by many other studies too [10].

The fact that affluent section of the society has affordability to spend money, and easy access to approach to restaurants, fast food outlets, facilities of motor vehicles and electronic gadgets as sedentary pursuits.

It is concluded from the present study that overweight and obesity among school- going children is major public health concern and an alarming state for the smaller cities like Aligarh. Lifestyle modifications like healthy eating habits, avoidance of fast foods high in sugar, fat and salt and emphasizing physical activity among school- children. Implementation of strategies like screening for overweight and obesity right from the beginning in schools accompanied by the counselling of parents and caregivers of school- children on their diet and acquiring healthy habits at family level. As children see their parents as ideals, it's a responsibility of every parent to become an example of living a healthy and disciplined life by becoming role model for them.

Present study has certain limitations like the study was done on school children only neglecting another important section of the society the non- school going children. This study cannot be generalized to the whole population there is a need for a larger study among general children residents so as to provide more decisive results about overweight and obesity and related risk factors.

Though, strength of our study lies in the fact that it gives an overview of the dual burden of nutritional disease among school-children in the age group of 7-12 years for the first time in Aligarh city and can demonstrate guidelines for future interventions on school and family level by the decision makers and health professionals.

\section{REFERENCES}

1. Yang Q, Xiao T, Guo J, Su Z, Complex relationship between obesity and the fat mass and obesity locus. Int J Mo I Med, 2017; 13 (5): 61529.

2. WHO, facts and figures, https://www.who.int/end-childhoodobesity/facts/en/.3 September, 2019.

3. Ibrahim L, and Allehdan S, Alassaf A and Tayyem R (2018), Iron deficiency and obesity in preschool children, Nutrition and Food Science, Vol 48 Issue: 3, 2018.

4. Cathoir KE O', Children's right to freedom from obesity: responsibilities of the food industry, Nordic Journal of Human Rights, 36:2, DOI:10.1080/18918131.2018.1505090.

5. Goyal RK, Shah VN, Saboo BD, Pathak SR, Shah NN, Gohel MC, Prevalence of overweight and obesity in Indian Adolescent School Going Children: Its relationship with socioeconomic status and associated lifestyle factors', JAPI2010; 58:151-18.

6. Bharati DR, Deshmukh PR, Garg BS, Correlates of overweight and obesity among school going children of Wardha city, Central India,2008.

7. Gupta S and Rathore R, Prevalence and Factors Influencing Obesity in Children Aged 6-14 Years belonging to Upper Middle-Income Group of Lucknow City, International Journal of Contemporary Medical Research 2016; 3(4): 10551057.

8. WHO Growth Reference; 2007. Availablefrom: http://www.who.int/growthref/who2007_bmi_for_age/en/index.html.

9. Thakre SB, Mohane SP, Ughade SM, Thakre SS, Morey SS, Humne AY Correlates of Overweight and Obesity among urban school going children of Nagpur city. J. of Clinical and Diagnostic Research. 2011 December, vol 5(8): 1593 - 1597

10. Nawab T, Khan Z, Khan IM and Ansari A, Is Small Town India Falling into the nutritional trap of metro crisis? A study in schoolgoing adolescents,2010.
11. Kalra S, Unnikrishnan AG, Obesity in India: The weight of the Nation. J Med NutrNutraceut [serial online] 2012, Available from: http//www.jmnn.org/text.asp?2012/1/1/37/94634.

12. Jagadesan S, RanjanI H, Miranda P, Unnikrishnan R, Anjana RM and Mohan V, Prevalence of Overweight and Obesity Among Schoo Children and Adolescents in Chennai, Vol 51_ issue 15 July, 2014.

13. Mahajan PM, Anil PJ, Singh Z, Johnson C, Murugan N, Sandeep A Senthilvel V, Study of Childhood Obesity Among School Children aged 6 to 12 years. in Union Territory of Puducherry. Indian J. of Community Medicine. Vol 36, issue 1, 1 January, 2011.

14. Hota S, Pangrahi RK, Mahilary N, Mohapatro S, Kumar SV, Mohanty S, Dietary Pattern amongst overweight and obese children, $9-15$ years. from government school in Bhubaneswar city. IOSR J. of Denial and Medical Sciences, Vol 14, issue 4, April 2015, PP 32 - 36.

15. Chaitali G, Mangala S, Hemalatha AJ, Pradeep C, Subrahmanyam G 'Childhood and adolescent overweight and obesity - A public health challenge in India', Int. J. of scientific study, Vol 2, July, 2014.

\section{AUTHORS PROFILE}

Aijaz Fatima: Research scholar, Department of Home Science, Faculty of Agricultural Sciences, Aligarh Muslim University, Aligarh, Uttar Pradesh, India Email: aijaztayyab1972@gmail.com

Prof. Anisa M. Durrani: Department of Home Science, Faculty of Agricultural Sciences, Aligarh Muslim University, Aligarh, Uttar Pradesh, India.

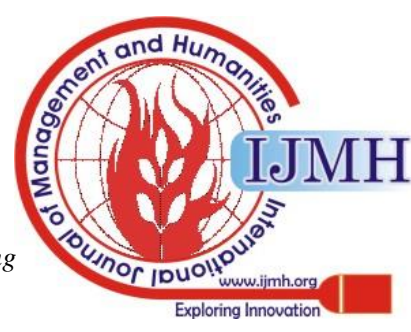

